\title{
"Ya marchamos... pero no solucionan el problema": protesta social y respuestas gubernamentales en torno a la inseguridad
}

\section{Miguel Armando López Leyva*}

Perfiles Latinoamericanos | Artículo vol. 23 | núm. 46 | 2015

pp. $91-120$

\section{Resumen}

Este artículo se propone, desde la perspectiva de las consecuencias políticas que generan los movimientos sociales, analizar cuán eficaces pueden ser cuando se involucran en el proceso de toma de decisiones del gobierno en la democracia mexicana. Basados en el estudio de las organizaciones de los movimientos sociales (oms) en contra de la inseguridad, a través de un esquema que empalma su acción con las fases del ciclo de la policy, se evalúa si logran incidir bajo el supuesto de que serán exitosos si logran llevar el tema a la atención gubernamental y, además, darle seguimiento a las acciones de las autoridades competentes.

\begin{abstract}
This article proposes, from the perspective of the political consequences generated by social movements, analyze how effective they can be when are involved in the decision making process in the context of the Mexican democracy. Based on the study of the social movement organizations (sMo) against insecurity, through a scheme that connects the action of the movements with the phases of the public policy, the article evaluates if they have an impact according to the following assumption: they will be successful if they take the issue to the governmental attention and, also, they are to be able to follow up the actions of the authorities.
\end{abstract}

Palabras clave: organizaciones de los movimientos sociales, protesta social, inseguridad pública, políticas públicas, democracia.

Keywords: social movements organizations, social protest, public insecurity, policy, democracy.

* Doctor en Ciencias Sociales con especialización en Ciencia Política por la Facultad Latinoamericana de Ciencias Sociales, Sede México. Investigador en el Instituto de Investigaciones Sociales de la Universidad Nacional Autónoma de México. 
n el estudio de la acción colectiva, una de las líneas de investigación que ha adquirido relevancia en los últimos años es aquella que trata de establecer vínculos entre los entornos políticos (democráticos o autoritarios) y el desempeño de los movimientos sociales (MS), ${ }^{1}$ cuya finalidad es dilucidar las condiciones que propician el surgimiento, desarrollo y fin de estos desafíos contenciosos, así como su éxito o fracaso en la consecución de sus objetivos (Della Porta, y Diani, 2000; Giugni, 1998 y 2004; Kriesi, 1995; McAdam, 1999; Tarrow, 1997).

En lo relacionado con el "éxito o fracaso", la literatura se ha concentrado en las consecuencias que los movimientos pueden producir en diversos ámbitos: cultural, social, económico y político. Los alcances de esas consecuencias son variados, así como los mecanismos utilizados para la obtención de los cambios propuestos; dependiendo del tipo de demandas enarboladas, del adversario que confronten, de los aliados que consigan y de las audiencias que los apoyen, serán los repertorios de acción que utilicen y las posibilidades de éxito o fracaso, traducido en el logro - o no- de sus metas.

Desde una perspectiva centrada en las consecuencias políticas, enfocada en la visibilidad de los cambios logrados, el presente artículo se propone mostrar los efectos que los movimientos generan en un ámbito muy específico, el de las políticas públicas $(\mathrm{PP}),{ }^{2}$ un aspecto de tratamiento reciente en la literatura del campo de la política contenciosa. ${ }^{3}$ Dicho en otros términos, una manera útil de observar las consecuencias que producen los Ms es mediante el ordenamiento de su acción en las fases del ciclo de las políticas, es decir, desde la definición de una situación problemática hasta el seguimiento de la política implementada.

$1 \quad$ Nos atenemos a una definición estándar de movimientos sociales, desde la corriente de interpretación que aquí se usa, a saber: son a) redes informales, basadas en b) creencias compartidas y solidaridad, las cuales se movilizan en torno a $c$ ) temas conflictivos, mediante $d$ ) el uso frecuente de formas variadas de protesta (Della Porta, y Diani, 2000).

2 Por políticas públicas entendemos, en términos generales, el proceso de toma de decisiones que involucra, principal pero no exclusivamente, a los distintos niveles y poderes de gobierno. Parsons (2007: 47) las define de este modo: "El significado moderno de la noción inglesa policy es tomar una medida o formular un plan, una serie de objetivos políticos, en contraposición a la 'administración’ [...]. Una política pública representa el intento de definir y estructurar una base racional para actuar o no actuar".

3 Giugni (2004: 2) justifica el estudio de las consecuencias en los términos en que nos proponemos hacer, de este modo: "tenemos aún poco entendimiento de las consecuencias de los movimientos sociales. Esto, en sí mismo, nos daría suficientes razones para prestar atención en este aspecto. Pero estudiar las consecuencias de los movimientos sociales es importante porque la gente se compromete en la acción colectiva precisa — aunque no exclusivamente - con el propósito de producir cambios en el mundo exterior, en particular en las decisiones políticas y en las políticas públicas". 
En lo particular, buscamos establecer en qué medida la acción de los Ms, en el entorno específico de la democracia mexicana en consolidación, ${ }^{4}$ puede o no influir en la respuesta institucional a sus agravios. Formulado en una pregunta: ¿de qué manera los movimientos pueden ser eficaces (obtener sus metas o ser "exitosos") cuando se involucran en la toma de decisiones de gobierno? La observación de cuánta capacidad de incidencia en el ciclo de las políticas tienen esos actores colectivos nos dirá cuánto pueden contribuir a modificar las características del contexto en el que se inscriben, siendo esta capacidad una consecuencia política que los movimientos producen en la democracia. Así, para ilustrar dicha incidencia, usaremos como caso de estudio la protesta social en contra de la inseguridad pública, que se desarrolló en dos contextos políticos relativamente distintos: 2004 y 2008.

El texto se divide en tres partes. En la primera se expone, a partir de dos propuestas teóricas, un esquema para definir la incidencia de los Ms en las fases del ciclo de las políticas, estableciendo en éste el modo en que esos desafíos contenciosos pueden influir en las decisiones de las autoridades y cómo esto, si refleja un logro, puede ser indicativo de algún grado de "éxito" (en cada fase o en su conjunto). En la segunda, se aplica el esquema de incidencia al caso de estudio solo para las dos primeras fases del ciclo: acceso a los canales institucionales de decisión y establecimiento de un tema en la agenda de gobierno, en los que se encuentran resultados exitosos. Para tal fin, se desarrollan principalmente dos aspectos: a) cómo la demanda por la inseguridad — que se expresa masivamente en dos movilizaciones - cobra visibilidad a través de los medios de comunicación y cómo esto contribuye a que esa relevancia se traslade al espacio del gobierno; y b) la manera en que las autoridades respondieron en lo inmediato al reclamo, con lo cual se hace palmaria su instalación en la agenda de gobierno.

En la tercera parte, el esquema es aplicado en las dos siguientes fases del ciclo: adopción del contenido de las políticas propuestas e implementación, fases en las que se encuentran fuertes límites para la acción contenciosa en tanto implican seguimiento, por lo cual los resultados exitosos se pueden valorar por su gradualidad, es decir, por avances lentos y parciales. En este apartado resultan fundamentales los diagnósticos públicos sobre los avances en materia de seguridad, así como la propia evaluación de los participantes de la protesta en las coyunturas citadas, y la percepción de algunos de ellos mediante entrevistas que fueron realizadas a propósito de este artículo.

4 Para un diagnóstico sobre la consolidación democrática en México, véase Cadena-Roa, y López Leyva (2011). 


\section{El encuentro de los movimientos sociales y las políticas públicas: un esquema para observar la incidencia}

Si el objetivo de este trabajo es observar las consecuencias que producen los movimientos sociales en las políticas públicas, entonces se puede recurrir a dos propuestas $^{5}$ que detallan cómo aquellos influyen en el ciclo —en una parte o en todo- de las políticas, esto es: en el establecimiento de la agenda, la formulación de alternativas, el diseño, la implementación y la evaluación. ${ }^{6}$ Dichas propuestas ofrecen un marco de evaluación de resultados a través del cual es posible considerar qué tanto los ms obtuvieron lo que demandaron y saber, de ese modo, si su influencia fue determinante en la consecución de los mismos (el "éxito"). Veremos más adelante cómo esta idea se adapta al estudio de las protestas sociales generadas en torno a la inseguridad.

La primera propuesta engloba los trabajos de Burstein et al. (1995) e Ibarra et al. (2002). En ambos grupos de autores se desglosan prácticamente las mismas fases del ciclo de las políticas ${ }^{7}$ pero, en el primer caso, se busca determinar cuáles son las respuestas de los sistemas políticos a las demandas de los movimientos (se le denomina "responsividad de las políticas"); en el segundo caso, se conceptualiza el impacto que generan los movimientos a partir de su intervención en cada fase del mencionado ciclo. En general, lo que se ilustra en esta propuesta de los autores referidos es la forma de incidencia que logran los movimientos a partir de la respuesta institucional que reciben.

Por otra parte, la segunda propuesta, de Amenta, y Young (1999), está delimitada al ámbito del Poder Legislativo exclusivamente. Dado que introducen como criterio principal la obtención de bienes colectivos, argumentan que es en el proceso legislativo en donde mejor se ve ese logro. Así, son tres momentos los que estos autores marcan como relevantes: establecimiento de la agenda

5 Cabe precisar que estas propuestas se inscriben en una de las corrientes de interpretación de la literatura de los movimientos sociales, la estructura de oportunidades politicas (EOP). Justamente la EOP, desde la perspectiva de las consecuencias políticas (resultados o impactos) que produce el desafío de estos actores colectivos, posibilita la valoración de los efectos que tienen los Ms en la respuesta estatal/ gubernamental a sus demandas. Y, como hemos dicho arriba, uno de los efectos observables está en las políticas públicas.

6 Conviene anotar que, para el análisis de México, el enlazamiento de actores sociales y políticas públicas ha sido trabajado por algunos autores, aunque no desde la perspectiva teórica propuesta aquí (véanse Canto, 2003 y 2006; Domínguez, 2011; Isunza, 2006; Gil, 2008; Vargas, 2011).

7 Las fases que utilizan Burstein et al. (1995) son: de acceso, agenda, políticas, resultado, impacto y estructural; las fases que usan Ibarra et al. (2002) son las siguientes: aparición, acceso, agenda, formulación, ejecución, impacto y estructural. En cada etapa se indica el modo en que los movimientos pueden incidir. 
política, establecimiento del contenido de la legislación, y promulgación de la legislación. ${ }^{8}$

Como resultado del cruce de estas propuestas —que abrevan del bagaje teórico de la literatura de las políticas_- ${ }^{9}$ presentamos un esquema que empalma la acción de los movimientos con las mencionadas fases del ciclo de las políticas públicas a través de la incidencia de aquellos en los distintos momentos de estas: ex ante, durante y ex post. La finalidad de esta estrategia metodológica es mostrar que el éxito de los ms depende estrechamente de su capacidad de dar seguimiento a las acciones de las autoridades comprometidas con la resolución de la demanda, una vez pasado el periodo de movilización (véase el cuadro 1).

Cuadro 1. Resultados de los movimientos sociales de acuerdo con su influencia en el ciclo de las políticas públicas

\begin{tabular}{|c|c|c|}
\hline $\begin{array}{l}\text { Fases del ciclo de } \\
\text { políticas públicas }\end{array}$ & Componentes de cada fase & $\begin{array}{l}\text { Resultado esperable } \\
\text { ("éxito") }\end{array}$ \\
\hline $\begin{array}{l}\text { 1. Acceso a los ca- } \\
\text { nales institucionales } \\
\text { de decisión. }\end{array}$ & $\begin{array}{l}\text { A. Formulación de una demanda (agravio) a partir de } \\
\text { la acción colectiva organizada. } \\
\text { B. Manifiesta disposición de las autoridades competen- } \\
\text { tes a atender la demanda expresada. }\end{array}$ & $\begin{array}{l}\text { Se accede a los espacios institucio- } \\
\text { nales de discusión y decisión públicos } \\
\text { (foros en el Legislativo, mesas de } \\
\text { negociación con el Ejecutivo). }\end{array}$ \\
\hline $\begin{array}{l}\text { 2. Establecimiento } \\
\text { (parcial o total) de } \\
\text { un tema en la agen- } \\
\text { da de gobierno. }\end{array}$ & $\begin{array}{l}\text { A. "Enmarcamiento" del agravio y difusión entre la } \\
\text { opinión pública. } \\
\text { B. Instalación del agravio en la agenda de gobierno } \\
\text { (efectos del "traslado de relevancia" temática). } \\
\text { C. Interlocución efectiva con las autoridades encarga- } \\
\text { das de la aprobación de las políticas. }\end{array}$ & $\begin{array}{l}\text { Se consideran las sugerencias del MS } \\
\text { de parte de las autoridades corres- } \\
\text { pondientes como soluciones tentativas } \\
\text { (una iniciativa de ley, un programa } \\
\text { social, medidas administrativas inme- } \\
\text { diatas y mediatas). }\end{array}$ \\
\hline $\begin{array}{l}\text { 3. Adopción } \\
\text { (parcial o total) del } \\
\text { contenido de las } \\
\text { políticas sugeridas. }\end{array}$ & $\begin{array}{l}\text { A. Participación en la definición de la viabilidad técnica } \\
\text { de la política por adoptar. } \\
\text { B. Cálculo efectivo de la factibilidad política (correlacio- } \\
\text { nes de fuerza en las instancias de decisión). }\end{array}$ & $\begin{array}{l}\text { Se asumen —en parte o en su } \\
\text { totalidad-las soluciones sugeridas } \\
\text { por el MS de parte de las autoridades } \\
\text { correspondientes. }\end{array}$ \\
\hline $\begin{array}{l}\text { 4. Implementación } \\
\text { de las políticas } \\
\text { adoptadas. }\end{array}$ & $\begin{array}{l}\text { A. Aceptación de las políticas en los términos en que } \\
\text { fueron aprobadas por las instancias correspondientes. } \\
\text { B. Incorporación a mecanismos institucionales de se- } \\
\text { guimiento y evaluación de los resultados programados. }\end{array}$ & $\begin{array}{l}\text { Se ejecutan y supervisan las políticas } \\
\text { adoptadas por las autoridades, en } \\
\text { correspondencia con la demanda } \\
\text { original planteada por el MS. }\end{array}$ \\
\hline
\end{tabular}

Fuente: Elaboración propia con base en Amenta, y Young (1999), Burstein et al. (1995), Ibarra et al. (2002) y McCombs (2006).

Puesto de manera más específica, el argumento que sostenemos es el siguiente: el éxito de los ms depende de su capacidad no solo para lograr una movilización numerosa, sino, además, para darle continuidad a los cursos de acción emprendidos por las autoridades involucradas en la resolución de las demandas enarboladas. En ese sentido, la capacidad de incidencia de aquellos será mayor

8 Para una revisión más detallada de estas propuestas, véase López Leyva (2012). En ese texto se realiza un ejercicio exploratorio de convergencia entre la literatura de las políticas públicas y la de los movimientos sociales, con algunas aplicaciones empíricas que ilustran su potencial explicativo.

9 Para una descripción de las fases del ciclo de las políticas, véanse Aguilar (2003), Bardach (1998), Knoepfel et al. (2007), Parsons (2007) y Subirats et al. (2008).

Perfiles Latinoamericanos | vol. 23, núm. 46, julio-diciembre de 2015 | FLAcso México Miguel Armando López Leyva | "Ya marchamos... pero no solucionan el problema": protesta social y respuestas gubernamentales en torno a la inseguridad | pp. 91-120 
en la medida en que logren ser partícipes de las diferentes etapas de la hechura de las políticas públicas; más aún, en que logren proponer contenidos concretos e involucrarse directa o indirectamente en su implementación.

Antes de continuar con la aplicación al caso elegido, resulta preciso anotar un par de apuntes metodológicos. El primero se refiere a la denominación del objeto de estudio. Si bien es cierto que las protestas en contra de la inseguridad es posible inscribirlas en el concepto amplio de Ms, también lo es que esto implicaría una limitación en el campo de observación sobre su incidencia en el ciclo de las políticas (máxime si el interés aquí es la observación de las "consecuencias políticas visibles”). ¿Qué parte del movimiento se observará? ¿Cómo podrá hacerse medible su contribución a la toma de ciertas decisiones en el ciclo? Así, para facilitar la comprensión de los efectos en las políticas, en este artículo se usará la noción organizaciones de los movimientos sociales (OMS) para designar al sector organizado de los mismos, en contraste con el no organizado. ${ }^{10}$

De acuerdo con Cadena-Roa (2008), los ms combinan acciones de ambos sectores:

Ningún ms se reduce a una sola oms ni a un solo conjunto de acciones no organizadas, sino que en ellos se combinan acciones planeadas por varias oms con acciones espontáneas que ninguna organización puede reivindicar $[\ldots]$ o quiere defender [...] El sector no-organizado de los Ms está compuesto por diversos públicos y por acciones espontáneas no-coordinadas [...] que favorecen, se oponen o se mantienen indiferentes frente a las acciones estratégicas de las oms. Entre más grandes son los ms, más numerosas y diversificadas son las oms que participan en ellos [...] el sector organizado de los MS sí está compuesto por OMS diferenciadas y autónomas, con objetivos específicos y procedimientos internos para definirlos y alcanzarlos. ${ }^{11}$

Lo anterior no solo "hace visible" nuestro objeto de estudio, además revela la interrelación necesaria dentro y fuera del propio Ms. Es decir, se puede reconocer que antes de estos episodios de protesta existían varias oms que trabaja-

10 McCarthy, y Zald (2003 [1977]: 172-173) definen la oms del siguiente modo: "es una organización formal y compleja, que identifica sus metas con las preferencias de un movimiento social o un contramovimiento, e intenta el logro de dichas metas". Esta definición es consistente con la de ms que aportan los mismos autores: "es un conjunto de opiniones y creencias de un sector de la población, el cual representa preferencias por el cambio de algunos elementos de la estructura social y/o distribución de beneficios de una sociedad".

11 Un abordaje similar a esta distinción, que puede ser complementario, es la distinción entre las fases "visible" y "latente" de los ms, de acuerdo con la conocida formulación de Melucci. En la primera fase prevalece la dimensión pública de la acción (manifestaciones, intervenciones en los medios de comunicación, entre otras), en la segunda predomina la acción dentro de las organizaciones y la producción cultural (Della Porta, y Diani, 2000). 
ban el tema de la inseguridad, en acción conjunta con los distintos niveles de gobierno, pero otras más se gestaron en las coyunturas de cada movilización, en ambos casos creando redes de colaboración entre ellas mismas y con las autoridades a las que apelaban. Cuando el trabajo de colaboración no es suficiente, estas OMs recurren a la movilización para hacer ostensible la ineficacia de la respuesta otorgada a sus demandas.

El segundo apunte es, en realidad, una aclaración necesaria sobre el alcance del presente artículo. Aquí no se asume la visión de que las posibles consecuencias "exitosas" de los ms o de las oms solamente dependan de lo que ellos hacen. Los estudiosos inscritos en la corriente de la estructura de oportunidades políticas (EOP) han establecido que el resultado que obtengan depende de la estructura del Estado, así como de una variedad de actores políticos y sociales que intervienen, sean aliados o adversarios. ${ }^{12}$ Pero, en estas líneas, esa no es la preocupación. Más bien interesa observar cómo pudieron incidir las oms en el ciclo de las políticas (¿de qué manera fueron eficaces?) sin detenerse a analizar los factores que explican la incidencia misma (¿por qué fueron o no eficaces?). En resumen, el propósito es conocer en qué grado fueron exitosas o no, sin dar cuenta de las causas de ese resultado.

Esta perspectiva, que pareciera limitada, es pertinente en la medida en que el abordaje en este artículo es el de un "estudio de caso". Al respecto, Giugni (2004: 9-10) establece que:

[...] los estudios de caso son más útiles cuando se está interesado en mostrar las consecuencias de movimientos en particular, en lugar de buscar los principios de variación de sus efectos como resultado de diferentes combinaciones de factores contextuales y situacionales [...] sólo un enfoque comparativo produce resultados que pueden ser generalizables más allá del caso específico bajo estudio.

\section{El tema en la agenda pública (y mediática): agravios, movilización y respuesta institucional}

Las protestas que encabezaron las oms en 2004 y 2008 articularon los reclamos (o agravios) de un conjunto de ciudadanos, y posibilitaron una amplia exposición pública y una atención por parte de los actores políticos. Además,

12 Como ejemplo de ello, Giugni, y Yamasaki (2009) argumentan que los resultados de esos desafíos colectivos dependen de dos factores: $a$ ) de la presencia de aliados poderosos en las arenas institucionales y de una opinión pública favorable (o ambos al mismo tiempo), y $b$ ) de que los temas que se discuten en el proceso decisional tengan bajo perfil (no sean tan relevantes). 
como podrá constatarse más adelante, tuvieron eco porque se desarrollaron en un contexto de creciente inseguridad, a raíz de la difusión de casos vinculados con hechos delictivos notables (llamados aquí "eventos catalizadores") y de una percepción pública preocupada por la evolución del problema a lo largo de los ańos. ${ }^{13}$

La movilización de 2004 se llamó "Rescatemos a México". Las noticias propagadas por la prensa en torno al aumento de los secuestros fueron fundamentales para su gestación. ${ }^{14}$ En especial, la demanda por mayor seguridad comenzó con motivo de una serie de secuestros exprés sucedidos en el centro comercial Perisur, al sur de la Ciudad de México. ${ }^{15}$ Ante las denuncias de los clientes por el incremento de delitos y la amenaza de realizar un boicot en contra del centro comercial, el entonces secretario de Seguridad Pública, Marcelo Ebrard, lanzó el operativo "Perisur Seguro", con 250 policías bancarios y preventivos de la Se-

13 A nivel regional hubo dos antecedentes notables: con motivo del incremento en casos de secuestro que venía ocurriendo desde comienzos de los años noventa, el 22 de febrero de 1995 se celebró en Lázaro Cárdenas una concentración masiva de quince mil personas (al día siguiente hubo otra en Uruapan); y con un motivo similar, aunque acentuado por la sospecha de colusión de las autoridades con los presuntos plagiarios, en septiembre de 1997 se llevaron a cabo movilizaciones en Cuautla y Cuernavaca, Morelos, que tuvieron como efecto que se separara del cargo, en 1998, el entonces gobernador (Ortega, 2008). A nivel nacional, hubo dos antecedentes notables de las movilizaciones de protesta que aquí se revisan. En 1997 se llevó a cabo una que concitó la atención de los medios y que llevó por nombre "México Unido contra la Delincuencia" (después, con este nombre cobró vida una organización dedicada a dar seguimiento a las políticas públicas en seguridad: MUCD). En 1998 se quiso replicar la movilización masiva de un ańo antes y se celebró otra, denominada "2a Marcha México Unido contra la Delincuencia”. Ambas marcaron el comienzo de la expresión pública de una preocupación extendida en muchos sectores de la población por los efectos perniciosos que provocaba la inseguridad en el país. No son objeto de estudio en este trabajo porque no produjeron la atención y respuesta gubernamentales que sí lo lograron las de 2004 y 2008, como veremos adelante; por eso es que en estas últimas es posible explorar las "consecuencias políticas visibles" dentro del ciclo de las políticas públicas.

14 En mayo se difunden una serie de noticias sobre secuestros y asesinatos que adquieren relevancia pública: las de los hermanos Vicente y Sebastián Gutiérrez Moreno (de nacionalidad mexicana y española, respectivamente), en mayo 17 y 24, y de la jefa de departamento del Instituto Federal de Acceso a la Información (IFAI), Lizbeth Itzel Salinas (mayo 19). El primer caso será objeto de controversia entre la embajadora de Espańa en México, Cristina Barros, y el entonces jefe de gobierno del DF, Andrés Manuel López Obrador (La Jornada, y El Universal, 18, 20 y 25 de mayo, 18 y 20 de junio de 2004, respectivamente).

15 Tómese en cuenta que, como consecuencia de la reforma política de 1996, Cuauhtémoc Cárdenas, del Partido de la Revolución Democrática (PRD), había ganado la Jefatura de Gobierno del Distrito Federal en 1997, luego de que la capital de la república estuviera hasta entonces bajo el mando de la Presidencia de la república —en manos del Partido Revolucionario Institucional (PRI)—, mediante la delegación de su facultad en un regente. En 2000 y en 2006, el PRD mantuvo la Jefatura de Gobierno del Distrito Federal, con Andrés Manuel López Obrador y luego Marcelo Ebrard Casaubón. A nivel federal, en 2000, el Partido Acción Nacional (pan) —en alianza con el Partido Verde Ecologista de México (PVEM) — se hizo de la Presidencia de la República, cuya titularidad quedó en manos de Vicente Fox Quesada; en 2006 ese partido refrendó su triunfo, sin alianza alguna, y el presidente fue Felipe Calderón Hinojosa. 
cretaría de Seguridad Pública (ssP). Empero, Ebrard aclaró entonces que en las últimas semanas solo se habían presentado una denuncia por secuestro exprés y cinco por robo (mayo 31) (La Jornada, y El Universal, 1 de junio de 2004). En este contexto, Guillermo Velasco, expresidente de MUCD e integrante del Consejo Ciudadano para la Seguridad Pública y la Justicia Penal (cCSPyjp), anuncia los preparativos para una gran marcha nacional en contra del secuestro (el 2 de junio), convocatoria a la que se sumarían pronto otras oms. ${ }^{16}$

La movilización de 2008 se denominó "Iluminemos México". El evento catalizador fue la noticia del asesinato del hijo de catorce años del empresario Alejandro Martí (1 de agosto), quien fuera secuestrado a mediados de año y por quien se había pagado ya un rescate. A raíz de este suceso trágico, ${ }^{17} \mathrm{el} \mathrm{empresa-}$ rio Elías Kuri Terrazas envía un correo electrónico a medios de comunicación, allegados y oms diversas, convocando a una movilización; el exhorto tuvo eco en el Movimiento Pro-Vecino, encabezado por Laura Elena Herrejón, quien a su vez se contacta con las demás asociaciones que formaron la expresión ciudadana "Iluminemos México", la cual haría una amplia convocatoria. ${ }^{18}$

Las dos grandes movilizaciones lograron concitar fuertemente la atención pública, si se mide por el grado de participación, intensidad y demandas que lograron articular. ${ }^{19}$ La del 27 de junio de 2004 tuvo una fuerte presencia me-

16 Un día después de este anuncio, se reúnen organizaciones civiles y empresariales para definir hora, estrategia y convocatoria para la marcha. A este evento asisten Arturo Mendicuti, de la Cámara Nacional de Comercio (Canaco); María Elena Morera, de MucD; Rosa María Navarro, de la Cámara Nacional de la Industria de la Transformación (Canacintra); Laura Elena Herrejón, del Movimiento Pro-Vecino; Alejandro Arvide, de Manos a la Obra; Fernando Shute, del Consejo Ciudadano de Seguridad Pública del Distrito Federal, y Ángel Corona, del Consejo Nacional de Seguridad (La Jornada, y El Universal, 3 y 4 de junio de 2004).

17 No obstante, otra serie de eventos relacionados tuvieron impacto antes y después del caso Martí, generando un clima de incertidumbre sobre la evolución del problema, a saber: el asesinato de Igor Labastida Calderón, funcionario cercano al secretario federal de Seguridad Pública, justo el mismo día en que se anunciaba que encabezaría un operativo anticrimen en el Distrito Federal y el Estado de México (26 de junio); la ejecución del abogado penalista Marcos Castillejos Escobar (9 de julio), ex subprocurador de la República, lo que provocó la reacción del gremio pidiendo que se nombrara un fiscal especial para atender el asesinato (10 de julio); la petición de la esposa de Nelson Vargas (ex titular de la Comisión Nacional del Deporte), Silvia Escalera, de que fuese devuelta su hija, secuestrada desde hacía casi un año, de quien no se había tenido noticia (25 de agosto) (La Jornada, y El Universal, 27 de junio de 2008; 10 y 11 de julio de 2008; 2 y 26 de agosto de 2008).

18 Se sumaron a esta convocatoria muchas oms, aunque los representantes de algunas de estas, emblemáticas de la marcha de 2004 (como María Elena Morera, presidenta de MUCD; Meyer Klip, presidente del Consejo Ciudadano de Seguridad Pública y Procuración de Justicia, y José Antonio Ortega, presidente del ccspyjp), asistirían en calidad de ciudadanos, según su propia versión (Reforma, 17 de agosto de 2008; El Universal, 20 de agosto de 2008).

19 Las demandas de 2004 se concentraron en diez temas: impunidad, ministerio público, juicios penales, actuación política transparente, combate al secuestro, prevención del delito, derechos de las víctimas, cultura de la legalidad, sistema penitenciario y participación ciudadana. Esta lista la entregan las oms 
diática y canalizó la insatisfacción de las oms involucradas. De acuerdo con lo que reportó la prensa escrita, se organizaron movilizaciones en el Distrito Federal y en aproximadamente 22 entidades más; los reclamos de justicia se dieron por igual en contra de las autoridades de todos los niveles, tanto locales como federales, siendo una proclama insistente la implementación de un programa inmediato contra el plagio. Las cifras de asistencia en el Distrito Federal variaron según la fuente, aunque todos coincidían en lo sorprendente de la movilización: 350 mil personas, de acuerdo con los organizadores; cuatrocientas mil, de acuerdo con el periódico El Mundo; 250 mil, registraron las agencias noticiosas EFE y CNN; quinientas mil, en el cálculo del periódico Reforma; la Secretaría de Seguridad Pública no emitió estimación alguna (La Crónica de Hoy, Milenio Diario, Reforma, El Universal, 28 de junio de2004).

A diferencia de la anterior, la protesta del 30 de agosto de 2008 tuvo un inusitado reflejo en los medios de comunicación y concentró la atención de una buena parte de la opinión pública. Con mayor énfasis al mostrado en las ocasiones previas, se extendió un fuerte reclamo hacia las autoridades políticas y un tono apartidista en las posturas de los actores convocantes y participantes. Las demandas se concentraron en expresiones como " $¡ S i$ no pueden, renuncien!", “¡No más secuestros, no más violencia!”, “¡Por un México seguro!” y “¡Ya basta!". De acuerdo con lo reportado en la prensa escrita, fueron 25 ciudades las que se movilizaron en esta protesta, con una participación estimada de poco más de 84 mil personas. En el Distrito Federal, la participación estimada fue de ochenta mil personas, según datos de la Secretaría de Seguridad Pública del Distrito Federal, y 350 mil, según cálculos extraoficiales (Excélsior, Milenio Diario, La Jornada y El Universal, 31 de agosto de 2008).

\footnotetext{
convocantes mediante un documento dirigido al Ejecutivo, a la Cámara de Diputados y a los gobiernos de las entidades federativas un par de días antes de que la marcha tuviera lugar; además de enlistar los puntos referidos, le exigen a las autoridades citadas resultados y acciones en contra de la delincuencia (Reforma, 25 de junio de 2005). En la movilización de 2008 también se promovieron diez puntos: 1) impulsar iniciativas a favor del mejoramiento de las condiciones de seguridad pública desde varios ámbitos de competencia; 2) promover foros de participación de los tres poderes para construir iniciativas en materia de seguridad pública; 3) impulsar la implantación de reformas en materia de justicia penal en los ámbitos federal y locales; 4) revisar y promover la aplicación de penas más severas; 5) impulsar iniciativas que atendieran las causas de la inseguridad; 6) fortalecer las asignaciones presupuestales para la prevención del delito en sus diferentes manifestaciones; 7) promover la participación de la sociedad civil en los programas de prevención social del delito en sus diferentes manifestaciones; 8) gestionar la implantación de recuperación de espacios públicos; 9) fomentar la implantación de tecnologías de la información para la prevención del delito y canalización de denuncia ciudadana; y 10) impulsar reformas que promovieran, en los tres niveles de gobierno, la adopción del trabajo comunitario para reos y menores infractores como un medio de restitución y readaptación social (Iluminemos México, [en línea], disponible en <www.iluminemosmexico.org.mx>).
} 
Ahora bien, ¿cómo se instaura el reclamo por la incapacidad estatal para resolver la inseguridad, enarbolado por las OMs, en el espacio de la política formal? ¿Cuál fue la reacción inmediata de los gobiernos a las demandas expuestas en ambos episodios de protesta (la "responsividad de las políticas")? Para valorar si las oms lograron ser exitosas en las dos primeras fases del ciclo, enlazaremos dos aspectos: la exposición del problema (agravio) en los medios de comunicación y la respuesta gubernamental inmediata. A partir de la exposición de este par de puntos podremos argumentar si fue exitoso en: $a$ ) tener acceso a los canales institucionales de decisión, y $b$ ) establecer el tema en la agenda de gobierno (enmarcado de un modo particular).

\section{Los medios}

Si asumimos que lo que hagan los ms "debe aparecer en los medios de comunicación” (Ibarra, 2005: 166) y que su función es expandir audiencias y contribuir a modificar la dinámica de la hechura de las políticas (Gerston, 1997), podremos comprender la influencia determinante que tienen en la búsqueda de los movimientos por ser incorporados en el proceso de toma de decisiones. Esa influencia resulta evidente en la jerarquización de temas para que sean asumidos como prioridades de gobierno. ${ }^{20}$

A fin de mostrar ese vínculo con los medios, recurrimos a lo que en la sociología de las noticias se llama "traslado efectivo de relevancia desde la agenda mediática hasta la pública”, según la formulación de McCombs (2006). ${ }^{21}$ Con base en esta sugerente idea, aquí se muestra el "traslado de relevancia" en el tema de la inseguridad, a fin de ilustrar cómo una preocupación latente en la ciudadanía puede reflejarse en la atención que una parte de los medios — las

20 Aunque existe un debate sobre su influencia en términos de "manipulación de la realidad" o creación de temas, algunos estudiosos han concluido que la influencia de los medios es determinante porque moldea los issues que se exponen en el espacio público (es decir, informan sobre las condiciones reales de los problemas) (véanse Majone, 2006; Tamayo, y Carrillo, 2005).

21 McCombs (2006) seńala que los medios son medios que recuperan las preocupaciones ciudadanas sobre problemas concretos, las expanden y difunden entre una audiencia más amplia y, como resultado, contribuyen a colocarlas como objeto de la atención gubernamental. La medición del "traslado de relevancia” parte de cruzar información relativa a los problemas que más preocupan a los ciudadanos (con fundamento en encuestas) — la agenda del público_ — y los temas que tratan los medios de comunicación (a partir de un registro puntual de la atención que le prestan por semanas) — la agenda mediática- El ejercicio que aquí se realiza reproduce esa mecánica doble al establecer, por un lado, la envergadura del problema de la inseguridad mediante la percepción que se registra en las encuestas (en México y América Latina) y, por el otro, al indicar el efecto posible de ciertos eventos aunque solo a nivel de la prensa escrita (sin ser un análisis sistemático y causal del vínculo entre dichas agendas). 
portadas de la prensa escrita— le brinda. ${ }^{22}$ La relevancia temática que los medios le dieron a las movilizaciones fue muy amplia. En 2004, toda la prensa escrita revisada registró como primer titular la marcha, destacando temáticamente los encabezados en dos sentidos: sorpresa por la multitudinaria protesta y exigencia ciudadana de resultados a las autoridades. En el caso de la reunión - tres semanas después - del Consejo Nacional de Seguridad Pública (CNSP), cinco de los seis periódicos dieron importancia al anuncio del entonces presidente Vicente Fox respecto al aumento del gasto en el combate a la inseguridad (no obstante, en solo cuatro de ellos la noticia destacó como encabezado principal).

Para 2008, la reunión del CNSP antecedió a la movilización ciudadana. Destacó que en el Consejo haya participado Alejandro Martí porque cuatro de los seis periódicos hicieron uso de la expresión que lanzó en ese evento para denotar la importancia de la circunstancia: "si no pueden, renuncien". ${ }^{23}$ Este reclamo enmarcó el transcurrir de la marcha — - según vimos líneas atrás- y de las crónicas periodísticas de un día después, aunque solamente un periódico - $\mathrm{La}$ Jornada, el único medio que no le dio el primer titular a este evento- lo colocó como encabezado de su nota informativa (véanse las crónicas publicadas en La Jornada y Milenio Diario, 31 de agosto de 2008).

En consonancia con este reclamo generalizado por la situación de inseguridad, puesto de relieve por los medios a partir de la protesta, el tema era uno de los más sensibles tanto en México como en América Latina. Como lo ha sugerido Powell (2004: 95) al referirse, en su modelo de responsividad, a la conexión entre los hacedores de políticas y los deseos de los ciudadanos, el statu quo cuenta mucho: "El contexto en el cual los ciudadanos están viviendo modela inevitablemente su percepción de la importancia y el contenido de las políticas que prefieren [...] Es difícil obtener las preferencias ciudadanas alejadas de sus contextos". Así, en lo relativo a los "contextos", la evolución temática de la inseguridad, sin dejar de ser preocupante en los años de estudio, es menos grave de lo que su percepción establece.

22 Según McCombs (2006: 107), "las noticias de portada del diario tienen unas dos veces más lectores que las que aparecen en páginas interiores. Las que llevan gráficos atractivos y titulares grandes atrapan la atención de más lectores". Para efectos del presente ejercicio, se recurrió a la revisión de las primeras planas de los principales periódicos en los dos ańos de interés (2004 y 2008): La Crónica de Hoy, Excélsior, La Jornada, Milenio Diario, Reforma y El Universal. Con ello pretendemos fijar el tratamiento que le otorgaron a dos sucesos concretos en cada año: las reuniones del Consejo Nacional de Seguridad Pública (CNSP) (como antecedente/consecuencia de las movilizaciones) y la realización misma de las marchas.

23 La expresión fue dicha así: "Señores, si piensan que la vara es muy alta, si piensan que es imposible hacerlo, si no pueden, renuncien, pero no sigan ocupando las oficinas de gobierno, no sigan recibiendo un sueldo por no hacer nada, que eso también es corrupción” (Reforma, 22 de agosto de 2008). 
De acuerdo con Arzt, y Vázquez Mercado (2010), entre 1995 y 2007 la tasa de homicidios dolosos mostró una tendencia descendente, pues se redujo más del 40\% (lo que se corrobora cuando este dato se compara con la tasa de mortalidad de la Secretaría de Salud). Para Escalante (2009), en términos generales, el número de víctimas por homicidios bajó sistemáticamente entre 1992 y 2007 (en todos los estados, salvo alguna excepción): de 14520 que había en 1990, pasó a 8507 en 2007 (una reducción de más de un tercio). Además, visto el fenómeno en términos de tasa nacional (número de víctimas por cada cien mil habitantes), el descenso es más notorio en relación con el aumento poblacional en el lapso referido: de un promedio de 19.72 pasó a 8.04 en $2007 .{ }^{24}$

Si tomamos en cuenta los datos de denuncias por secuestro - uno de los delitos más sensibles para las OMs—, sin considerar la "cifra negra" existente, ${ }^{25}$ encontraremos que 2000 y 2007 presentan el mayor número de casos, 591 y 596, respectivamente, y los años intermedios muestran un número inferior, que tuvo su mínima expresión en 2004: 323 (ssp, 2008). Visto desde la perspectiva de las averiguaciones previas iniciadas a raíz de las denuncias, las cifras son idénticas, aunque aquí se agrega una, la de 2008, que se elevó en casi 40\% (820 averiguaciones previas) (MUCD, 2009).

Ahora bien, en lo relativo a las percepciones, de acuerdo con Consulta Mitofsky (2010), la inseguridad ha sido uno de los dos problemas principales de preocupación de los ciudadanos mexicanos entre 2001 y 2008: entre 2001 y 2004, y 2007 y 2008 fue el segundo problema percibido, y en 2005 y 2006 fue el primero, seguido por la crisis económica. A nivel de América Latina, la agenda ha estado marcada desde 1995 por dos problemas principales: el desempleo y la delincuencia. La delincuencia ha mostrado un crecimiento constante: desde el 5\% de los entrevistados que en promedio lo consideraba el problema más importante de su país (en 1995), hasta el 19\% que ocupa en la última medición del Latinobarómetro que aquí interesa (2009). Cabe señalar que el desempleo ocupó el primer lugar entre 1995 y 2007 como problema

24 No obstante, en un texto posterior, el mismo autor establece que, en el periodo 2008-2009, la tendencia de homicidios se disparó de un modo "absolutamente improbable", dado que la tasa nacional regresó a los niveles de 1991, rompiendo una tendencia de veinte ańos: dicha tasa subió $50 \%$ en 2008 y otro $50 \%$ en 2009; en números absolutos significa que en el primer ańo hubo 5500 homicidios más que en 2007, y en el segundo, 5800 más que en 2008. En otras palabras, el número de víctimas por homicidio pasó de 8507 en 2007 a 19809 en 2009, y la tasa nacional pasó de 8.04 a 18 entre los mismos ańos (Escalante, 2011).

25 Según el cálculo de Herrera (2009), el total de actos delictivos - tanto del fuero federal como del común- podría ser en realidad 5.4 veces mayor que los que se denuncian. 
percibido, y fue en 2008 cuando pasó a segundo plano (15\%), desplazado por la delincuencia $(17 \%) .^{26}$

Con lo anterior se ha querido mostrar cómo los medios capturaron una preocupación social presente no solo en el ambiente del país (y de América Latina), sino en las oms promotoras de las movilizaciones en los dos años de estudio. La importancia de estas en los medios ofrece suficiente evidencia de cuán efectiva puede ser la acción de los Ms cuando buscan atraer la atención gubernamental hacia un tema de interés generalizado. De ello depende, en buena medida, la respuesta que se logre. ${ }^{27}$

\section{La respuesta institucional}

¿Cuál fue la respuesta gubernamental a este reclamo colectivo, problematizado exitosamente por las oms y registrado extensamente por los medios? ¿Cómo respondieron las autoridades a la visibilización del problema de la inseguridad lograda por las oms en los dos años? Porque en ambos episodios de protesta quedó claro que se impugnaba a los gobiernos en sus distintos niveles ante la falta de solución efectiva con el transcurrir de los años. ${ }^{28}$ En ese tenor, las respuestas gubernamentales fueron inmediatas a la movilización, incluso le antecedieron en algunos casos, dada la magnitud del problema, la importancia mediática adquirida por el tema y sus repercusiones en el debate público nacional. ${ }^{29} \mathrm{En}$

26 En coincidencia con estas cifras, el Iberobarómetro de 2008 muestra que el problema que más preocupa a los ciudadanos de la región (incluyendo a Espańa y Portugal) es la inseguridad, con un 17\% de las opiniones (seguido del desempleo y la corrupción, ambos con 15\%). Del conjunto de naciones estudiadas, solamente tres tienen niveles de aceptación del manejo de la seguridad superiores al 50\% (Panamá, Colombia y Argentina) mientras que México está en un 44\% (Flores, 2008).

27 Si lo planteamos en términos del esquema de McCombs (2006), una preocupación mayoritaria del público (inseguridad/delincuencia, de acuerdo con las encuestas) capturó la atención de los medios (prensa escrita en los periodos 2004 y 2008); y los medios trasladaron esta preocupación hacia las autoridades, que la colocaron en un lugar prioritario. Así, la agenda del público (un problema acuciante del entorno) tuvo cabida en la agenda mediática (un problema que se recoge y expone, coincide con el problema público) y, por la fuerza adquirida con la exhibición del problema, este se trasladó a la agenda de gobierno (se hace objeto de la acción gubernamental).

28 En las encuestas se mostraba claramente contra quién se protestaba. De acuerdo con Parametría (2008), la protesta de ese ańo se perfilaba contra todas las autoridades en un $40 \%$, y luego contra el presidente en un 26\%; un cambio importante en relación con la percepción de cuatro años antes (2004), cuando la gente decía protestar primero en contra de todas las autoridades con un 44\%, luego en contra del jefe de gobierno del Distrito Federal, con $12 \%$, y contra el presidente de la república, con $11 \%$. Es decir, en 2008 la responsabilidad principal se percibía a nivel federal más que a nivel local.

29 En la opinión pública había un contraste entre las perspectivas de solución del problema y la respuesta gubernamental esperada. En 2004, en una encuesta publicada antes de la realización de la marcha (Reforma, 2004), el 48\% de los entrevistados estaba de acuerdo con la afirmación "La marcha ayudará 
razón del papel fundamental del Ejecutivo federal y sus atribuciones en la materia, la atención se concentró en sus acciones y declaraciones, y dicho papel lo compartió con el jefe de gobierno del Distrito Federal.

En torno a las dos movilizaciones promovidas y encabezadas por las diferentes OMs, hubo actos de gobierno significativos que focalizaron las preocupaciones de los funcionarios públicos; los de mayor relevancia — por su simbolismofueron las reuniones del CNSP. En 2004, la reunión tuvo lugar varios días después de la marcha, con el anuncio previo del entonces presidente Vicente Fox de que convenía una reestructuración del Consejo para hacerlo más operativo como instrumento eficaz de mando y decisión en contra de la delincuencia. En la XV sesión de esa instancia de coordinación gubernamental, el presidente hizo el ofrecimiento de mil millones de pesos adicionales para el combate a la delincuencia (La Jornada, y El Universal, 29 de noviembre de 1997; 14 y 15 de julio de 2004).

En 2008, un par de reuniones del Consejo marcaron claramente las acciones gubernamentales y las perspectivas de solución del problema. Días antes de la marcha, el 21 de agosto, se firmó el Acuerdo Nacional por la Seguridad, la Justicia y la Legalidad (ANSJL), un compromiso político y de politicas, en el que se establecieron 75 medidas contra la delincuencia, con objetivos específicos por instancia de gobierno y tiempo de ejecución para cada uno. ${ }^{30}$ Se propusieron cien días de plazo para evaluar sus avances. Finalizado el plazo, en otra sesión del Consejo (el 28 de noviembre), el gobierno federal, en voz del secretario de Gobernación, reconocería que se había avanzado en siete de las tareas pactadas pero que no era posible celebrar ningún avance hasta que hubiese tranquilidad y seguridad en los hogares de los mexicanos (Reforma, 22 de agosto y 29 de noviembre de 2008).

En las coyunturas previas y posteriores a la protesta pueden apreciarse declaraciones de gran envergadura — algunas de ellas emitidas en cadena nacional-, que fijaban posturas sobre el tema o justificaban las acciones emprendidas para

a reducir la delincuencia en la ciudad”, contra un $47 \%$ que pensaba que no; una proporción diferente arroja otro ejercicio demoscópico, en el que el 59\% de los entrevistados aseguraba que la marcha solo serviría como desahogo de la gente, pero que no disminuiría la delincuencia (IPSOs-BIMSA, 2004). En contraste, la misma encuesta de Reforma (2004) revelaba que el 70\% de los entrevistados estaba de acuerdo en que dicho acto ayudaría a que las autoridades combatiesen más fuertemente la delincuencia, mientras que la levantada por IPSOS-BIMSA (2004) destacaba que el 74\% de los entrevistados consideraba que la marcha obligaría a que las autoridades hicieran un mejor trabajo. Para 2008 las tendencias son similares, quizás menos pesimistas en el primer aspecto (resolución del problema) y menos optimistas en el segundo (atención gubernamental) (Parametría, 2008; Reforma, 2008).

30 En el acto de firma del Acuerdo participaron varias de las oms involucradas en ambas movilizaciones; destacaban Alejandro Martí, presidente de la Fundación Fernando Martí, y María Elena Morera, presidenta de MUCD. 
atenderlo y no dejarlo crecer, todas en respuesta a la exigencia ciudadana. En 2004, el presidente Fox transmitió un mensaje a la nación en el que proponía diez medidas urgentes para combatir el problema de la inseguridad y se comprometía a rendir cuentas en un plazo de sesenta días. Por su parte, el jefe de gobierno del Distrito Federal, Andrés Manuel López Obrador, mantuvo una estrategia discursiva en dos pistas: en la primera, demeritaba el valor de la manifestación cargándolo de una intencionalidad negativa, por la participación de empresarios y otros personajes de "derecha" como promotores de la misma; en la segunda, reconocía que la inseguridad seguía siendo el gran desafío de su administración a pesar de los avances logrados (La Jornada, y El Universal, 29 de junio, 2 y 7 de julio de 2004) (véase López Leyva, 2014).

En 2008, el día posterior a la marcha, el presidente Felipe Calderón recibió a los representantes de las oms, quienes le entregaron un documento con ocho demandas a los poderes de la Unión y doce peticiones a las 32 entidades federativas. El presidente, en un mensaje a los medios en la residencia oficial de Los Pinos, aceptó como suyas las demandas que se le planteaban y convino en dar respuesta a aquellas que estaban en el ámbito de sus atribuciones, además de comprometerse a revisar todos los puntos expuestos en reunión del CNSP. Ese mismo día, el jefe de gobierno del Distrito Federal, Marcelo Ebrard, en un tono distinto al de su antecesor en el cargo, tuvo su propia reunión con dichos representantes, a quienes dio como respuesta un plazo de un mes para evaluar los avances. El secretario de gobierno del Distrito Federal, José Ángel Ávila, fue el encargado de dar un mensaje público: expresó su beneplácito por la participación masiva en la marcha y aseguró que el jefe de gobierno coincidía plenamente con la necesidad de poner en operación un plan en contra la inseguridad (La Jornada, y Milenio Diario, 1 de septiembre de 2008).

En síntesis, podemos argüir que la agenda del público (problemas) se proyectó en la agenda de los medios (temas) de una manera (casi) directa, lo cual produjo que los gobiernos — federal y del Distrito Federal, principalmenteatendieran esta causa de forma prioritaria, instalándose así el problema como un asunto en la agenda de gobierno. En ese sentido, las oms utilizaron el espacio generado por los medios, a partir de una preocupación ciudadana muy extendida, para atraer el interés de las autoridades, comprometerlas en reuniones conjuntas y exigirles acciones eficaces en el corto, mediano y largo plazo. Los medios hicieron de la inseguridad un asunto de tratamiento constante, lo que permitió que la atención de las diferentes instancias de gobierno fuera expedita y diera pie a discutir y presentar alternativas de solución. Si lo apreciamos desde el mirador del esquema propuesto en este artículo, podemos decir que las OMs fueron exitosas en las dos primeras fases del ciclo de las políticas, como se observa en el cuadro 2. 
Cuadro 2. Resultados de las oms vistos desde el ciclo de las políticas públicas

\begin{tabular}{|c|c|c|}
\hline Fase & Componentes concretos de cada fase & $\begin{array}{l}\text { Resultados concretos esperables } \\
\text { (en términos de "éxito") }\end{array}$ \\
\hline 1 & $\begin{array}{l}\text { A. Organización y realización de las marchas con } \\
\text { motivo de la percepción de creciente inseguridad } \\
\text { y la incapacidad estatal para resolver el problema. } \\
\text { Los "eventos catalizadores" disparan la organiza- } \\
\text { ción colectiva. } \\
\text { B. Declaraciones de las autoridades ejecutivas y } \\
\text { legislativas sobre la legitimidad de la demanda } \\
\text { y la pertinencia de las movilizaciones. }\end{array}$ & $\begin{array}{l}\text { Éxito: se accede a los espacios institucionales } \\
\text { de discusión y decisión públicos: } \\
\text { Participación en reuniones del CNSP, donde los } \\
\text { representantes de las OMS son voceros del reclamo } \\
\text { y demandantes de soluciones. } \\
\text { Reuniones de los representantes de las OMS con } \\
\text { los Ejecutivos federal y local, los días anteriores } \\
\text { y posteriores a la protesta, para exigir acciones } \\
\text { eficaces. }\end{array}$ \\
\hline 2 & $\begin{array}{l}\text { A. Uso intensivo de los medios para enmarcar el } \\
\text { problema y difundirlo con claridad ("Ya basta", "Si } \\
\text { no pueden, renuncien"). Configuración de una opi- } \\
\text { nión pública favorable a la búsqueda de soluciones } \\
\text { al problema. } \\
\text { B. La difusión "enmarcada" influye para que se le } \\
\text { considere un problema público. El gobierno federal } \\
\text { reordena prioridades y da muestras claras de volun- } \\
\text { tad para atender el problema. } \\
\text { C. Mantenimiento del tema en la agenda de } \\
\text { gobierno varios meses después de pasadas las } \\
\text { movilizaciones. }\end{array}$ & $\begin{array}{l}\text { Éxito: se consideran las sugerencias de las OMS } \\
\text { de parte de las autoridades correspondientes como } \\
\text { soluciones tentativas: } \\
\text { Formulación de propuestas de los representantes } \\
\text { de las OMS; partes firmantes de acuerdos con las } \\
\text { autoridades (el principal: el ANSJL) con compromi- } \\
\text { sos verificables. } \\
\text { Participación en reuniones de evaluación en el } \\
\text { CNSP, donde los representantes de las OMS son crí- } \\
\text { ticos de los avances planteados por las autoridades. }\end{array}$ \\
\hline 3 & $\begin{array}{l}\text { A. Promoción de iniciativas de ley y de medidas } \\
\text { específicas. } \\
\text { B. Cabildeo con las instancias de decisión } \\
\text {-Poderes Ejecutivo y Legislativo- para negociar } \\
\text { el contenido de las decisiones. }\end{array}$ & $\begin{array}{l}\text { Poco éxito: se asumen en parte las soluciones } \\
\text { sugeridas por las OMS de parte de las autoridades } \\
\text { correspondientes. Algunos logros: } \\
\text { Creación y funcionamiento del Observatorio Ciuda- } \\
\text { dano de la Justicia (Poder Judicial). } \\
\text { Aprobación de la Ley General para Prevenir y San- } \\
\text { cionar los Delitos en Materia de Secuestro (Poderes } \\
\text { Ejecutivo y Legislativo). }\end{array}$ \\
\hline 4 & $\begin{array}{l}\text { A. Evaluaciones negativas de las OMS en torno al } \\
\text { avance de las políticas de seguridad (vs. índices } \\
\text { de delincuencia). } \\
\text { B. La división de las OMS dificulta acceder a los es- } \\
\text { pacios institucionales de monitoreo de las políticas } \\
\text { por parte de las autoridades competentes. }\end{array}$ & $\begin{array}{l}\text { Sin éxito: se ejecutan y supervisan las políticas } \\
\text { adoptadas por las autoridades, en correspon- } \\
\text { dencia con la demanda original planteada por } \\
\text { las OMS. } \\
\text { Participación constante en instancias de discusión, } \\
\text { sin efectos prácticos. } \\
\text { Seguimiento y evaluación hecho por las OMS de lo } \\
\text { pactado (en particular en el ANSJL), sin respuestas } \\
\text { claras de las autoridades. }\end{array}$ \\
\hline
\end{tabular}

\title{
El desvanecimiento del interés público (y gubernamental). Expectativas frustradas y cambios graduales
}

\author{
¿Qué pasa después del momento expresivo del agravio? ¿Qué ocurre una vez que \\ se ha capturado la atención — de la opinión pública y de los gobiernos — en el \\ problema construido? ¿Qué se obtiene después de conseguir entablar diálogo \\ con las autoridades sobre la necesidad de atender la situación social problemá- \\ tica identificada? ¿Hay resultados de políticas que permitan valorar otro ám- \\ bito del éxito de las oms? A partir de la revisión de las posturas y opiniones de \\ dichas organizaciones sobre su propia percepción de incidencia en las políticas,
}


se podrá argumentar si fueron exitosas o no en las siguientes dos fases del ciclo de las políticas públicas. ${ }^{31}$

En los meses y años subsecuentes a las protestas de 2004 y 2008, algunas de las principales oms emitieron su valoración sobre lo que se había logrado de los compromisos exigidos y pactados con los diferentes niveles de gobierno. Especialmente el periódico Reforma, que incluyó en su propia agenda editorial el tema de la inseguridad, se dio a la tarea de darle cobertura a dichas organizaciones, y fue, quizás, el único que se preocupó por proporcionar información acerca de lo que se había logrado y aquello que quedaba por hacer.

A unos meses de haberse celebrado la movilización de 2004, Eduardo Gallo, en ese entonces consejero de enlace del MUCD con las autoridades, anunciaba que no se había podido concretar la creación del Instituto Nacional Ciudadano de Seguridad Pública y Justicia, uno de los ofrecimientos del presidente Fox cuando había recibido a los representantes de las oms. Gallo estimaba que esta situación era explicable porque en el gobierno había tanto miedo a la participación ciudadana, como falta de voluntad política (Reforma, 16 de noviembre de 2004). En lugar del proyectado instituto, sería instalado meses después el Consejo Ciudadano para la Prevención del Delito de la Secretaría de Seguridad Pública federal (Reforma, 24 de junio de 2005).

$\mathrm{Al}$ ańo de celebrada aquella movilización, Reforma (25 de junio de 2005) dio cuenta de los avances y pendientes de las demandas de las organizaciones involucradas. De acuerdo con el reporte evaluatorio, de las diez peticiones que se hicieron, cinco habían sido "atendidas" mientras que las restantes requerían cambios legales, por lo que en estas no se había visto mucho avance. En sentido similar, algunos de los representantes de las oms —-Laura Elena Herrejón, del Movimiento Pro-Vecino, y Víctor Meléndez, del Club Rotario, entre otrosse pronunciaron por avanzar en los muchos temas pendientes, reconociendo que se habían experimentado avances en la materia; además, exigieron que el

31 Se tiene conciencia de que, al guiarse por la percepción de los líderes de las oms, no se consideran otras maneras posibles de valorar el "éxito" en la política pública. No obstante, un aspecto clave para valorar la eficacia es la percepción acerca de la propia actividad contenciosa. Ello quiere decir que, de cómo evalúen sus capacidades de influencia y las condiciones políticas e institucionales de su entorno, dependerá en buen grado la consecución de sus objetivos. Si perciben una valoración positiva del tema de su interés —en este caso, el de la inseguridad que, hemos visto, estaba presente en el ambiente público, lo que facilitó su inclusión en la agenda de gobierno - les resulta más fácil generar una amplia movilización social, aunque no consideren necesariamente que tendrá un impacto inmediato y contundente en la toma de decisiones de los gobiernos en sus distintos niveles. Este es un paso posterior que requiere menor grado de movilización y mayor grado de articulación organizativa. Si las oms perciben que su capacidad de incidencia se debilita al momento de materializar los efectos en políticas, por razones externas o internas, será más difícil presionar a las autoridades para orientar su definición en el sentido deseado. Un ejemplo de la importancia del estudio de las percepciones para mostrar la incidencia de las organizaciones de la sociedad civil en políticas públicas puede verse en Cemefi (2011) y en Cortés (2011). 
gobierno informara a los ciudadanos acerca de las acciones implementadas a un año de la movilización (Reforma, 28 de junio de 2005).

Sin embargo, esta perspectiva medianamente optimista se tornó en su contrario en la evaluación de los dos años. En el acto en el que se conmemoró la movilización, mediante la colocación de un moño blanco en la Torre Latinoamericana, y mantas con la leyenda "Exijo Seguridad" en más de diez edificios ubicados en importantes vías de la ciudad, María Elena Morera del MUCD, evaluaba de este modo el resultado: "El sistema de seguridad y justicia está fracasado, tienen que reestructurarlo [...] Esperamos que el nuevo Gobierno, sea quien sea, tenga un compromiso, y nosotros vamos a tomar esfuerzos con el que salga (electo), pero también le vamos a exigir" (Reforma, 28 de junio de 2006)..$^{32}$ De acuerdo con su versión, seguían sin cumplirse las cinco peticiones que estaban pendientes al año de la marcha. ${ }^{33}$

De similar manera, los avances se consideraban mínimos en los momentos posteriores a la movilización de 2008. A los cien días de firmado el ANSJL, el documento clave para la política en contra de la inseguridad, algunos de los representantes de las oms daban su perspectiva sobre lo que se había hecho para combatir la inseguridad. Para José Antonio Ortega, del Consejo Ciudadano para la Seguridad Pública y la Justicia Penal, como en ese lapso habían sido secuestradas y asesinadas 22 personas, el acuerdo demostraba su fracaso por falta de resultados: "siguen los secuestros, sigue la inseguridad" (Reforma, 28 de noviembre de 2008). En la sesión del CNSP en la que se evaluarían los avances, María Elena Morera, del MUCD, diría de forma tajante: "Las cosas no están mejor que la última vez que nos encontramos aquí. El acuerdo no basta, la voluntad no basta. Los hechos cuentan, pero también las víctimas. ¿Cuántas más, señores?” (Reforma, 29 de noviembre de 2008).

Morera daría a conocer, después de su participación en dicha instancia colegiada, los resultados del seguimiento hecho a los 75 puntos de ANsJu. De acuerdo con su informe, se habían alcanzado cinco puntos pactados, lo que representaba 7\% de avance (Milenio Diario, 29 de noviembre de 2008). En este sentido, la nota optimista la daba el Poder Judicial, pues a casi seis meses de celebrada dicha movilización, ya había cumplido nueve de los diez compromisos

32 Este acto se celebraba a unos días de las elecciones de 2006, de las que saldría electo como presidente Felipe Calderón Hinojosa, en uno de los procesos electorales más controvertidos de los últimos tiempos.

En el mismo acto, Rosa María Navarro, coordinadora nacional de Seguridad de la Cámara Nacional de la Industria de la Transformación (Canacintra), afirmaba: "Lo más importante que dejó la marcha fue que se logró el acercamiento con las autoridades y que hicieron caso a los ciudadanos" (Reforma, 28 de junio de 2006). En esa dirección, tanto Laura Elena Herrejón (2011) como María Elena Morera (2011) coinciden, en entrevistas, en que fue un logro de la movilización de 2004 sacar del olvido el tema de la seguridad y lograr que el gobierno le pusiera atención. 
que le correspondían del ANSJL. Más aún, con la creación y funcionamiento del Observatorio Ciudadano de la Justicia, propuesto por el entonces presidente de la SCJN, y en el que participarían en su comité directivo tres OMS: MUCD (con Ana Franco), Iluminemos México (con Elías Kuri) y sos (con Alejandro Martí), parecía expresarse la voluntad de este poder por abrirse al escrutinio público ciudadano a fin de supervisar sus acciones, deficiencias y necesidades (Reforma, 19 de marzo de 2009). ${ }^{34}$

Empero, meses después, el MUCD advertía del avance incipiente en sus demandas. A partir de un diagnóstico sobre sus diez peticiones, las cuales formaban parte del ANsJL, la organización señalaba que el avance era apenas del $20.5 \%$ global. El rubro menos atendido era el establecimiento de mecanismos de justicia alternativa en materia penal, con solo $2.5 \%$ de avance; en contraste, la demanda mejor evaluada era la del acceso a la información en materia de seguridad pública, con 32.5\% (Reforma, 13 de mayo de 2009). Quizás por esa razón, ante la inminencia de los comicios intermedios de 2009, el MUCD optó por comprometer la firma de los dirigentes de los principales partidos políticos en un acuerdo sobre diez propuestas en materia de seguridad (Reforma, 11 de junio de 2009).

$\mathrm{Al}$ año de realizada la movilización, el MUCD hizo una nueva evaluación relacionada con el cumplimiento de metas del ANsJL. El resultado era pobre, solamente se habían cumplido en su totalidad siete de los sesenta puntos comprometidos en el Acuerdo. Si se juzgaba el avance por nivel de gobierno, el resultado era: el Ejecutivo había cumplido uno de 28 compromisos que le correspondían, el Legislativo tres de siete, el Judicial dos de diez y los gobiernos estatales ninguno (de siete). En contrapartida, y siguiendo con esta evaluación, de los catorce compromisos cuya responsabilidad era de las organizaciones, todos se habían cumplido.

Para Ana Franco, dirigente del MUCD, el incumplimiento desacreditaba los compromisos con las autoridades, porque la calificación global del acuerdo era de 4.8. "Ya no creemos en más acuerdos", sentenciaría la dirigente (Reforma, 19 de agosto de 2009). Pero no solamente el MUCD se pronunció sobre los resultados insatisfactorios, también lo hicieron otros representantes de oms como Alejandro Martí, de sos ("es inaceptable que haya sectores importantes que no hayan hecho nada, y eso yo creo que los ciudadanos no lo debemos permitir"), y Laura Elena Herrejón, del Movimiento Pro-Vecino ("ya marchamos, ya se

34 Este optimismo lo confirmaban otros dirigentes, como Laura Elena Herrejón, del Movimiento Pro-Vecino ("el Poder Judicial es el área con la que mejor hemos podido trabajar y avanzar desde la marcha y desde que se signó el acuerdo") y Elías Kuri, de Iluminemos México ("nos abre una ventana de posibilidades que debemos saber aprovechar con responsabilidad y eficacia") (Reforma, 19 de marzo de 2009). 
firmaron acuerdos, ya se tomaron fotos, ya dieron discursos, pero no solucionan el problema”) (Reforma, 19 y 29 de agosto de 2009).

En el segundo aniversario de la marcha de 2008, el periódico Reforma evaluó treinta de los 75 puntos firmados en el ANsjL (Ortega, 2010). Se consultó entonces con los representantes de las principales oms y coincidieron en que el avance era parcial en las metas del Acuerdo - asumiendo que faltaba transparencia para evaluarlas- y que no se había experimentado mejoría en la reducción de los índices delictivos. No obstante, un punto importante era el establecimiento de precedentes como lo resumió María Elena Morera (otrora dirigente del MUCD, y luego de Causa en Común):

Sin duda es el Acuerdo más importante que se ha firmado en este tema. Sin embargo, no generó el impacto que todos esperábamos, pero sentó varios precedentes: convocó a diversos actores de la sociedad y a todas las instancias públicas, fijó tiempos y obligó a que la opinión pública volteara la atención, con orden y responsabilidad, a un tema que se le había dejado sólo al gobierno y que no ha cumplido bien (Ortega, 2010). ${ }^{35}$

A pesar del incumplimiento generalizado de los compromisos, principalmente por parte de los poderes públicos, uno de los logros obtenidos a raíz de la presión ejercida por las movilizaciones de 2004 y 2008 fue la aprobación de la Ley General para Prevenir y Sancionar los Delitos en Materia de Secuestro, en 2010. ${ }^{36}$ Una de las promotoras de ello fue Isabel Miranda de Wallace (Alto al Secuestro), quien había propuesto con anterioridad la expedición de una ley general de protección a las víctimas del delito del secuestro. La norma finalmente aprobada establece, entre otras cosas, que el delito del secuestro no prescribe, y especifica las distintas modalidades existentes, así como sanciones severas para aquellos secuestradores miembros de las policías y fuerzas armadas (Milenio Diario, 8 de octubre de 2010). ${ }^{37}$

35 Si se traduce la declaración de Morera en los términos del esquema propuesto en este artículo, se puede decir que el tema se instaló en la agenda de gobierno, pero sin efectos claros en las otras etapas del ciclo de las políticas.

36 El secuestro fue el tema principal que originó las preocupaciones de las oms; las víctimas y familiares relacionados con estos casos fueron los que organizaron las movilizaciones que dieron vida a este movimiento entre 1997 y 2008. Por eso la aprobación de esta ley es tan importante; su simbolismo es inevitable.

37 La iniciativa fue presentada por el Ejecutivo en febrero de ese año, el Senado la aprobó —con modificaciones - en abril, y la Cámara de Diputados hizo lo suyo en octubre. El Ejecutivo la publicó el 30 de noviembre. En el acto de aprobación de la ley por la Cámara de Diputados estuvieron presentes Miranda de Wallace y Martí. En un comunicado conjunto, ambos personajes destacaron que la forma en que se elaboró dicha ley muestra que en la sociedad civil organizada "existe el conocimiento y la in- 
Lo expuesto hasta ahora revela que el panorama en general es negativo en términos de resultados. No obstante, algunos de ellos se consiguieron a partir de propuestas de las oms involucradas en el tema, o bien, de compromisos cumplidos por parte de las autoridades responsables: por ejemplo, el Observatorio Ciudadano de la Justicia o la Ley General para Prevenir y Sancionar los Delitos en Materia de Secuestro. En línea con esta apreciación, representantes de algunas oms, entrevistados a propósito de este artículo, dan su versión sobre la escasez de resultados en relación con su percepción de baja incidencia en políticas. En la formulación de sus posturas se verá como coincidencia que la limitación más fuerte para obtener resultados radica en la forma en que interactúan las organizaciones entre ellas mismas y con las autoridades responsables de enfrentar el problema. ${ }^{38}$

Eduardo Gallo (2011), vinculado por muchos años al MUCD, organización que presidió entre 2010 y 2011, convocó a la movilización de 2004 —a título personal y como miembro del Consejo Directivo- pero no lo hizo en la de 2008. Las razones de su desencanto se concentran en los "muy pobres" resultados obtenidos en la primera manifestación, lo cual le hizo perder credibilidad y confianza en las marchas como instrumento de cambio. Lo que explica esos resultados - y la disolución del interés gubernamental en el combate a la inseguridad, una vez que ha pasado la etapa de la movilización- es la inexperiencia de los participantes ("todos habíamos llegado por azares del destino, porque había sido alguien víctima de la delincuencia”), así como la lógica de los políticos en la que se inscribió su acción ("ahí te doy dos o tres dulces para que parezca que estoy trabajando”). En esta interpretación, Gallo dice que es la "cooptación" o el alineamiento de las organizaciones hacia el gobierno federal el elemento más importante para explicar el poco avance.

Para Laura Elena Herrejón (2011), dirigente del Movimiento Pro-Vecino, una de las principales oms promotoras de la protesta, las marchas significan presión para el gobierno, para los delincuentes y para la sociedad misma. Pero dicha presión social no basta a la hora del seguimiento. En 2004 y en 2008 lo relevante era la voluntad de trabajar fuera de los reflectores, voluntad que pocas

teligencia para participar en la conformación de leyes que efectivamente solucionen problemáticas que afectan directamente al ciudadano [...] la aprobación de la ley marca un antes y un después en la relación entre el Poder Legislativo y la ciudadanía, puesto que durante meses estuvimos insistiendo en la necesidad de la aprobación de la ley y con beneplácito participamos en las discusiones de la minuta en el seno de las comisiones" (El Universal, 8 de octubre de 2010).

38 Como ya se precisó, este artículo pretende mostrar cómo pueden ser eficaces ("exitosos") los movimientos en la consecución de sus objetivos dentro del ciclo de las políticas públicas; para ese fin, se argumentó que su capacidad de incidencia depende de lograr movilización social y seguimiento continuo en todas las etapas del ciclo. En ese sentido, las razones que exponen los entrevistados aclarando por qué se llegó a determinado resultado abonan a ese argumento, pero el propósito no ha sido explicar el resultado mismo. 
organizaciones tienen ("si no hay alguien dándole seguimiento, rápidamente [los tres poderes y los tres niveles de gobierno] dejan en el cajón del olvido los acuerdos y los compromisos"). En relación con el ANsJL, considera que los resultados son escasos, en buena medida porque se hizo "sobre las rodillas", sin consultar a las organizaciones que lo signaron, y porque "sirvió para la foto nada más", pues pocos puntos se han cumplido de los que quedaron establecidos en él.

Elías Kuri (2011), principal promotor de la marcha en 2008 y presidente de la asociación civil Iluminemos México (nombre heredero del que tuvo la misma movilización), considera que el desafío concreto para organizadores y participantes es transitar del sentimiento (la manifestación) a la acción (el seguimiento). Kuri encuentra, como problema principal para la acción posterior de las OMS, la falta de unión y coordinación entre ellas ("no podemos ponernos de acuerdo, no podemos unirnos, no somos tolerantes, no estamos de acuerdo en ceder ni dos centímetros"). Este problema afectó tanto el seguimiento del ANSJL como los propios compromisos derivados de la movilización. ${ }^{39}$

María Elena Morera (2011), presidenta del MUCD durante cinco años (20032008), considera que la utilidad de las marchas es limitada porque es un acto expresivo, a lo que le sigue una labor más ardua, la del seguimiento ("darle seguimiento necesita una organización mucho más amplia de la sociedad civil”). Es justo ahí en donde encuentra el límite de la acción organizada, porque la gente no entiende que las marchas no resuelven los problemas, después de ellas vienen muchas otras cosas, en las cuales pocos participan ("porque la gente tiene muchas cosas que hacer, la gente no está teniendo una visión de largo plazo, no está pensando que tenemos que construir entre todos, no, y nos cuesta más trabajo esa parte"). ${ }^{40}$

Finalmente, José Antonio Ortega (2011), vinculado en sus orígenes al MUCD —donde fue secretario cuando presidió la organización Guillermo Velasco

39 Kuri menciona que este problema se originó por un diferendo entre las organizaciones que lo respaldaban y aquellas que tenían un trabajo previo en el tema de la seguridad, como el MucD: el diferendo versó sobre la pertinencia de incorporar al ANSJL los diez puntos originalmente planteados en la convocatoria de Kuri ("los 10 puntos de Iluminemos México, se sumaron a los puntos del Acuerdo Nacional de Seguridad, con eso se controlaban esos 10 puntos"). Herrejón habla de otro problema en 2008, la disputa por la coordinación de la marcha — que recayó en la entrevistada—, dado que varias de las organizaciones integradas en la convocatoria querían destacar y encabezarla.

Según Morera, lo central para lograr un seguimiento apropiado de las decisiones de gobierno es la distribución adecuada de trabajo entre las distintas organizaciones, así como vencer la desconfianza. La falta de vertebración entre organizaciones (ponerse de acuerdo en la repartición de los temas), junto con la persistencia de "puntos clientelares" en la sociedad civil (productor de cooptación de muchas de esas organizaciones) es lo que explica que la participación social se vea limitada en sus efectos. Otro nudo problemático que se agrega a lo anterior ha sido la multiplicidad de temas que se proponen como parte de las demandas ("al final yo creo que nosotros también nos hemos equivocado como sociedad civil en subir muchos temas a la mesa").

Perfiles Latinoamericanos | vol. 23, núm. 46, julio-diciembre de 2015 | FLacso México Miguel Armando López Leyva | "Ya marchamos... pero no solucionan el problema": protesta social y respuestas gubernamentales en torno a la inseguridad | pp. 91-120 
Arzac - y actual dirigente del Consejo Ciudadano para la Seguridad Pública y la Justicia Penal, A.C., fue promotor de las movilizaciones de 1997 y 2004, y participante en la de 2008. Para él, una parte del problema de los resultados es la "falta de voluntad política" de las autoridades: existe cuando la sociedad se expresa en las calles, presiona y exige su actuación inmediata; pero cuando estas condiciones desaparecen, la voluntad se disipa. La razón por la que no hacen caso las autoridades, por la que los logros son pocos, se funda en la división entre las oms, de la cual se derivan la falta de presión sobre la autoridad y la dispersión de objetivos. ${ }^{41} \mathrm{El}$ punto clave es, entonces, la presión sobre las autoridades, porque "al no tener consistencia, continuidad, unidad, un objetivo común, el efecto se pierde”.

Junto con la evaluación negativa que hacen las oms de las acciones desarrolladas a partir de las propuestas elaboradas por ellas y de los compromisos asumidos por las autoridades responsables (en lo particular aquellos contraídos en el ANSJL), se observa como factor crítico, digno de estudio, el seguimiento de las políticas de gobierno, ${ }^{42}$ como se ha hecho visible en las opiniones de los entrevistados. ${ }^{43} \mathrm{Si}$ lo anterior lo apreciamos desde la perspectiva del esquema propuesto en este artículo, se puede decir que las oms no lograron ser exitosas

41 En sus palabras: "no logramos sentarnos a la mesa y hacer un objetivo común quienes participamos en la organización; hubo divisiones, no hubo una visión clara, no hubo unidad, hubo protagonismo, división, insensibilidad de aprovechar ese poder que te dio el haber convocado a esa gran movilización".

Una posible explicación, que debería ser objeto de otro artículo para el caso que aquí se expone, es la que aporta Vargas (2011:132) en relación con las organizaciones no gubernamentales: "Desafortunadamente, las ONG no están en posibilidades de administrar eficientemente la fase de implementación, debido a sus pocas habilidades gerenciales y su fuerte concentración en los esquemas participativos. Contrariamente a los supuestos generalmente manejados por los estudios sobre redes, en la etapa de implementación de las políticas la tendencia es que los actores entran en conflicto más que en procesos cooperativos. Eso posiblemente se debe a que se inicia una etapa de lucha de intereses, en la que hay ganadores y perdedores. Los actores, entonces, tratan de minimizar sus costos y maximizar sus recursos y beneficios." Buscaglia (2013: 146-147) ha escrito, refiriéndose específicamente al tema de la inseguridad, que la clave se encuentra en "[...] que todos los grupos de la sociedad civil organizada logren establecer una agenda mínima de demandas que defiendan hasta el final [...] La sociedad civil mexicana, infiltrada por élites que dependen y nacen del poder político corrompido, se ha conformado simplemente dándole visibilidad a los problemas, viendo cómo se generan negocios de auditorías a modo y reparación de dańos a víctimas, y se usa a éstas como carne de cañón para proyectos políticos y económicos [...] sólo limitarse a concienciar (con marchas, foros y publicaciones) sobre los problemas sociales y políticos que azotan a una población que ya conoce sus cánceres de inseguridad humana es subestimar las capacidades sociales". De acuerdo con estas opiniones, la escasez de resultados y la falta de seguimiento de las políticas se debe a: la inexperiencia de los participantes y la lógica predominante de los políticos (Eduardo Gallo); la necesidad de voluntad para trabajar fuera de los reflectores — no todos están dispuestos a hacerlo(Laura Elena Herrejón); la falta de unión y coordinación entre las organizaciones (Elías Kuri); la falta de una organización más amplia de la sociedad —no todos participan de esta otra etapa— (María Elena Morera), y, finalmente, a la falta de voluntad política de las autoridades aunada a la división entre las organizaciones (José Antonio Ortega). 
en las siguientes dos fases del ciclo de las políticas (aunque tuvieron algunos logros parciales), como se puede observar en el cuadro 2 .

\section{A manera de cierre}

Las oms examinadas han expresado una clara intención de incidir en la toma de decisiones en la cuestión de la seguridad pública, aunque sus efectos hayan sido diferenciados. A partir del esquema propuesto en estas líneas (cuadros 1 y 2), es posible afirmar que, en las primeras dos fases, mediante: a) la capacidad de movilización y enmarcamiento del agravio logrados, b) el tratamiento dado por los medios al problema, y $c$ ) las respuestas inmediatas de los distintos niveles de gobierno, las oms lograron ser exitosas en tanto que $a$ ) lograron acceso a los canales institucionales de decisión —a través de la interlocución con los poderes públicos - y establecieron el tema de la inseguridad en la agenda de gobierno, y b) al conseguir que se introdujera en los debates con las autoridades diagnósticos y soluciones tentativas al problema percibido.

Pero en las siguientes dos fases, en las que se requiere de menor movilización y mayor coordinación organizativa, el resultado es otro (con algunos frutos meritorios)..$^{44}$ En este sentido, la valoración del resultado de la acción de las OMs, desde su propia percepción, debe tomar en cuenta que es fundamental el seguimiento a los gobiernos federal y estatales, en sus distintas ramas - ejecutiva, legislativa y judicial—, cuando el tratamiento y resolución del problema público pasa por distintos canales de la toma de decisiones (lo cual marca, per se, su complejidad).

Se puede decir que el estudio de estas oms muestra que las expectativas en torno a la resolución del problema disminuyen pasado el momento de la movilización, y que las respuestas gubernamentales se corresponden con el impulso reactivo inmediato de los manifestantes y con la magnitud del asunto. En el mediano plazo, la eficacia de la acción colectiva disminuye en la medida que la presión social se desvanece y el trabajo de interlocución con las autoridades pierde visibilidad (aunque requiera ser continuo y sistemático). De este modo, los "éxitos" que las oms cosechen tenderán a ser parciales e incrementales, de acuerdo con la propia evolución de las condiciones institucionales que definan el ciclo de las políticas públicas.

44 Algunos de esos logros citados aquí, fruto de la presión permanente y seguimiento constante de algunas organizaciones en las instancias en donde correspondía su resolución, han sido los casos del Observatorio Ciudadano de la Justicia y de la Ley General para Prevenir y Sancionar los Delitos en Materia de Secuestro. Son ejemplos palpables de éxito que, sin embargo, no agotan la agenda de asuntos por resolver. 


\section{Referencias}

\section{Bibliohemerografía}

Aguilar, Luis F., 2003, "Estudio introductorio", en Luis F. Aguilar Villanueva (ed.), Problemas públicos y agenda de gobierno, 3a. ed., México, Miguel Ángel Porrúa, pp. 15-72.

Artz, Sigrid, y Guillermo Vázquez del Mercado, 2010, "Violencia en México: realidades y perspectivas", Istor, año XI, núm. 42 (otońo), pp. 41-59.

Amenta, Edwin, y Michael P. Young, 1999, "Making an Impact: Conceptual and Methodological Implications of the Collective Goods Criterion", en Marco Giugni et al. (eds.), How Social Movements Matter (eds.), Minneapolis, University of Minnesota Press, pp. 22-41.

Bardach, Eugene, 1998, Los ochos pasos para el análisis de politicas públicas: un manual para la práctica, México, CIDE/M. Á. Porrúa.

Burstein, Paul et al., 1995, "The Success of Political Movements: A Bargaining Perspective", en J. Craig Jenkins, y Bert Klandermans (eds.), The Politics of Social Protest. Comparative Perspectives on States and Social Movements. Vol. 3: Social Movements, Protest, and Contention, Minneapolis, University of Minnesota Press, pp. 275-295.

Buscaglia, Edgardo, 2013, Vacios de poder en México. Cómo combatir la delincuencia organizada, México, Debate.

Cadena-Roa, Jorge, 2008, "Evaluación del desempeño de los movimientos sociales", en Cristina Puga y Matilde Luna (coords.), Acción colectiva y organización. Estudios sobre desempeño asociativo, México, IIS-UnAM, pp. 265-301.

Cadena-Roa, Jorge, y Miguel Armando López Leyva, 2011, "La consolidación de la democracia en México: avances y desafíos (2000-2006)", Estudios Sociológicos, vol. xxviI, núm. 86 (mayo-agosto), pp. 415-462.

Canto, Manuel, 2006, "Políticas públicas: participación e institucionalización”, ponencia presentada en el XI Congreso Internacional del CLAD sobre la Reforma del Estado y de la Administración Pública, Ciudad de Guatemala, 7-10 de noviembre.

Canto, Manuel, 2003, Lo civico en lo público: estrategias y herramientas de incidencia ciudadana en las políticas públicas, México, Centro de Estudios Sociales y Culturales Antonio Montesinos.

Cemefi, 2011, Una fotografía de la sociedad civil en México. Informe analitico del Índice CIVICUS de la Sociedad Civil 2010, México, Centro Mexicano para la Filantropía/crvicus/Iniciativa Ciudadana para la Promoción de la Cultura del Diálogo. 
Cortés, Lorena, 2011, Estudio comparado sobre la incidencia de las organizaciones de la sociedad civil en politicas públicas. Análisis de percepción a partir del Índice de la Sociedad Civil en países de América Latina, tesis de Maestría en Políticas Públicas Comparadas, México, Flacso México.

Della Porta, Donatella, y Mario Diani, 2000, Social Movements. An Introduction, Oxford, Blackwell.

Domínguez Virgen, J. Carlos, 2011, "Ventanas de oportunidad y coaliciones de política pública: el caso del proyecto para un nuevo aeropuerto en la ciudad de México desde una perspectiva histórica”, Secuencia, núm. 79 (enero-abril), pp. 63-88.

El Universal, de mayo a julio de 2004; de junio a agosto de 2008; 8 de octubre de 2010.

Escalante Gonzalbo, Fernando, 2011, “Homicidios 2008-2009”, Nexos, núm. 397 (enero), pp. 36-49.

Escalante Gonzalbo, Fernando, 2009, “Homicidios 1990-2007”, Nexos, núm. 381 (septiembre), pp. 25-31.

Excélsior, 28 de junio de 2004; 15 de julio de 2004; 22 y 31 de agosto de 2008.

Flores, Ramiro, 2008, "Democracia. Entre la consolidación y el desencanto", Nexos, núm. 372 (diciembre), pp. 22-24.

Gerston, Larry N., 1997, Public Policy Making. Process and Principles, Nueva York, M. E. Sharpe.

Gil García, Carlos, 2008, "Problemas, territorios y organizaciones en la acción pública: Los dilemas de la decisión en el caso del nuevo aeropuerto de la Ciudad de México”, en Julio Labastida Martín del Campo, Miguel Armando López Leyva, y Fernando Castaños (coords.), La democracia en perspectiva: consideraciones teóricas y análisis de casos, México, IIS-UNAM, pp. 307-336.

Giugni, Marco, 2004, Social Protest and Policy Change: Ecology, Antinuclear, and Peace Movements in Comparative Perspective, Lanham, MD, Rowman \& Littlefield.

Giugni, Marco, 1998, "Introduction. Social Movements and Change. Incorporation, Transformation, and Democratization”, en Marco G. Giugni et al., From Contention to Democracy, Lanham, MD, Rowman \& Littlefield, pp. xi-xxvi.

Giugni, Marco, y Sakura Yamasaki, 2009, “The Policy Impact of Social Movements: A Replication through Qualitative Comparative Analysis”, Mobilization, vol. 14, núm. 4 (diciembre), pp. 467-484.

Perfiles Latinoamericanos | vol. 23, núm. 46, julio-diciembre de 2015 | FLacso México Miguel Armando López Leyva | "Ya marchamos... pero no solucionan el problema": protesta social y respuestas gubernamentales en torno a la inseguridad | pp. 91-120 
Herrera, Carlos (2009), "Inseguridad pública en México", Territorio y Economía, núm. 25 (primavera), pp. 39-47.

Ibarra, Pedro, 2005, Manual de sociedad civil y movimientos sociales, Madrid, Síntesis.

Ibarra, Pedro et al., 2002, "Los nuevos movimientos sociales. El estado de la cuestión”, en Pedro Ibarra et al., Creadores de democracia radical. Movimientos sociales y redes de políticas públicas, Barcelona, Icaria, pp. 23-55.

Isunza Vera, Ernesto, 2006, "Para analizar los procesos de democratización: interfaces socioestatales, proyectos políticos y rendición de cuentas", en Ernesto Isunza Vera, y Alberto J. Olvera (coords.), Democratización, rendición de cuentas y sociedad civil: participación ciudadana y control social, México, CIESAS/Universidad Veracruzana/M. Á. Porrúa, pp. 265-291.

Kriesi, Hanspeter, 1995, "The Political Opportunity Structure of New Social Movements: Its Impact on Their Mobilization”, en J. Craig Jenkins, y Bert Klandermans (eds.), The Politics of Social Protest. Comparative Perspectives on States and Social Movements. Vol. 3: Social Movements, Protest, and Contention, Minneapolis, University of Minnesota Press, pp.167-198.

Knoepfel, Peter, 2007, "Hacia un modelo de análisis de políticas públicas operativo. Un enfoque basado en los actores, sus recursos y las instituciones", Ciencia Politica, núm. 3 (enero-junio), pp. 6-38.

La Crónica de Hoy, 28 de junio y 15 de julio de 2004; 22 y 31 de agosto de 2008.

La Jornada, de mayo a julio de 2004; de junio a agosto de 2008; 29 de marzo y 7 de abril de 2011.

López Leyva, Miguel Armando, 2014, "Protesta social y acceso a la justicia: didáctica democrática en torno a disputas por el ejercicio de derechos", en René Millán Valenzuela (coord.), Vida pública en México: ¿Didáctica para la democracia?, México, IIs-UnAM, pp. 233-275

López Leyva, Miguel Armando, 2012, "Los movimientos sociales y su influencia en el ciclo de las políticas públicas”, Región y Sociedad, año xxrv, núm. 55 (septiembre-diciembre), pp. 159-197.

Majone, Giandomenico, 2006, “Agenda Setting”, en Michael Moran et al. (eds.), The Oxford Handbook of Public Policy, Oxford, Oxford University Press, pp. 228-250.

McAdam, Doug, 1999, "Orígenes terminológicos, problemas actuales y futuras líneas de investigación”, en Doug McAdam et al. (eds.), Movimientos sociales: perspectivas comparadas. Oportunidades politicas, estructuras de movilización y marcos interpretativos culturales, Madrid, Istmo, pp. 49-70. 
McCarthy, John D., y Mayer N. Zald, (2003 [1977]), “Social Movement Organizations”, en Jeff Goodwin, y James M. Jasper (eds.), The Social Movements Reader. Cases and Concepts, Malden, Blackwell, pp.169-186.

McCombs, Maxwell, 2006, Estableciendo la agenda. El impacto de los medios en la opinión pública y en el conocimiento, Barcelona, Paidós.

Milenio Diario, junio 2004; de agosto a noviembre de 2008; 8 de octubre de 2010.

Ortega, José Antonio, 2008, El secuestro en México, México, Planeta.

Ortega, Octavio, 2010, "Acuerdo secuestrado", Enfoque (suplemento del periódico Reforma), núm. 853, 22 de agosto, pp. 4-8.

Parsons, Wayne, 2007, Politicas públicas. Una introducción a la teoría y la práctica del análisis de políticas públicas, México, Flacso México/Miño y Dávila.

Powell, G. Bingham, 2004, "The Chain of Responsiveness", Journal of Democracy, vol. 15, núm. 4, pp. 91-105.

Reforma, 2008, "Encuesta (telefónica: DF, MTY, GDL y SAL)/Ven importante asistir”, 28 de agosto.

Reforma, 2004, "Encuesta (telefónica: DF)/Ven acto ciudadano", 26 de junio.

Reforma, de mayo a noviembre de 2004; junio de 2005 y 2006; de junio a noviembre de 2008; de marzo a agosto de 2009; 26 de abril y 1 de mayo de 2012 .

Subirats, Joan et al., 2008, Análisis y gestión de politicas públicas, Barcelona, Ariel.

Tamayo, Manuel, y Ernesto Carrillo, 2005, “La formación de la agenda pública”, Foro Internacional 182, vol. XLV, núm. 4 (octubre-diciembre), pp. 658-681.

Tarrow, Sidney, 1997, El poder en movimiento. Los movimientos sociales, la acción colectiva y la política, Madrid, Alianza.

Vargas, Saúl, 2011, "Evaluando la participación social: democracia y políticas públicas", Revista Mexicana de Sociología, vol. 73, núm. 1 (enero-marzo), pp. 105-137.

\section{Informes y encuestas}

Consulta Mitofsky, 2010, "Monitor Mitofsky. Economía, gobierno y política”, [en línea], México, disponible en <www.consulta.com.mx>.

Perfiles Latinoamericanos | vol. 23, núm. 46, julio-diciembre de 2015 | FLacso México Miguel Armando López Leyva | "Ya marchamos... pero no solucionan el problema": protesta social y respuestas gubernamentales en torno a la inseguridad | pp. 91-120 
IPSOS-BIMSA, 2004, "Encuesta telefónica: marcha contra la delincuencia (zona metropolitana del DF)", [en línea], México, disponible en <www.ipsos-bimsa.com.mx>.

Latinobarómetro, 2009, Informe 2009, [en línea], Santiago, Corporación Latinobarómetro, disponible en <www.latinobarometro.org $>$.

MucD, México Unido Contra la Delincuencia, 2009, Informe Secuestro 2009, [en línea], México, disponible en <www.mucd.org.mx>.

Parametría, 2008, "Sociedad mexicana pierde fe en marchas (encuesta nacional de vivienda)", [en línea], México, disponible en <www.parametria.com.mx>.

ssp, 2008, Programa Nacional de Seguridad Pública 2008-2012, [en línea], México, disponible en <www.ssp.gob.mx>.

\section{Entrevistas}

1. Gallo, Eduardo, 2011, activista social y expresidente de México Unido Contra la Delincuencia, México, D.F., 31 de marzo.

2. Herrejón, Laura Elena, 2011, dirigente del Movimiento Pro-Vecino, México, D.F., 22 de marzo.

3. Kuri, Elías, 2011, convocante y organizador de la marcha "Iluminemos México", México, D.F., 17 de mayo.

4. Morera, María Elena, 2011, dirigente de Causa en Común y expresidenta de México Unido Contra la Delincuencia, México, D.F., 15 de abril.

5. Ortega, José Antonio, 2011, dirigente del Consejo Ciudadano para la Seguridad Pública y la Justicia Penal, México, D.F., 22 de marzo.

\section{Páginas electrónicas}

Iluminemos México, <www.iluminemosmexico.org.mx>.

Recibido el 2 de junio de 2014. Aceptado el 12 de enero de 2015. 